\title{
Real-Time Measurement of Maximal Voluntary Breath-Holding Time in Patients with Obstructive Ventilatory Defects and Normal Controls
}

Raqueli Biscayno Viecili, Denise Rossato Silva, Paulo Roberto S. Sanches, André Frota Müller, Danton Pereira da Silva and Sérgio Saldanha Menna Barreto*

Hospital de Clínicas de Porto Alegre, Universidade Federal do Rio Grande do Sul (UFRGS), Brazil

\begin{abstract}
Background: Breath-holding test has been tested in some clinical scenarios and has proved to be of clinical utility.

Objectives: To determine the maximum voluntary breath-holding time in patients with obstructive ventilator defects and in normal subjects and to correlate the breath-holding times with pulmonary function tests.
\end{abstract}

Methods: We conducted a case-control study including patients with obstructive ventilator defects and a control group consisted of volunteers recruited in the same hospital, with normal spirometry. Spirometry was performed using a computerized spirometer. Breath-holding test was conducted using a pneumotachograph. All measured outputs were displayed in real time on a portable computer. The maximal voluntary apnea inspiratory and expiratory times (MVAIT and MVAET) were measured.

Results: A total of 35 patients with obstructive ventilatory defects (18 asthma and 17 COPD) and 16 controls met the inclusion criteria and were included in the analysis. The MVAIT was lower in COPD patients (21.6 \pm 12.6 seconds) than in controls $(31.5 \pm 15.7$ seconds) $(p=0.049)$. MVAET was also lower in COPD cases than in controls $(16.5 \pm 6.0$ vs $22.1 \pm 7.9 ; p=0.030)$. We found positive and significant correlations between MVAIT and FVC $(L)(r=0.656 ; p=0.004)$ and between MVAIT and FEV $(\mathrm{L})(r=0.518 ; p=0.033)$ in COPD cases. MVAET was also correlated with $F V C(L)$ $(r=0.505 ; p=0.039)$ and $F E V_{1}(L)(r=0.757 ; p<0.0001)$.

Conclusions: MVAIT and MVAET were significant lower in patients with obstructive ventilatory defects with COPD diagnosis than in controls, and they were correlated positively with FVC and FEV in COPD patients. Our results provide additional evidence of usefulness of MVAIT/MVAET as pulmonary function tests.

Keywords: Apnea; Breath-holding test; Spirometry; Maximal voluntary apnea inspiratory time

\section{Introduction}

Breath-holding is an unstable state with changes occurring in many interrelated variables. The breath-holding test is simple and rapid. The simplest objective measure of breath-holding is its duration. The maximal duration of voluntary apnea varies from subject to subject and depends on chemical and non-chemical stimuli [1].

Breath-holding time has been shown to be reduced by anything that increases feedback from diaphragm afferents (any tonic diaphragm activity and possibly arterial hypoxia and hypercapnia) or that increases the central respiratory rhythm (arterial hypoxia or hypercapnia, or decreasing lung volume, or increased metabolic rate) [2].

Breath-holding test has been tested in some clinical scenarios and has proved to be of clinical utility [3-5]. This test can serve as screening test, raising suspicion of obstructive ventilatory defects, and could be used as pulmonary function parameter like forced expiratory volume in the first second $\left(\mathrm{FEV}_{1}\right)$ and forced vital capacity (FVC).

The aim of the present study was to determine the maximum voluntary breath-holding time in patients with obstructive ventilator defects and in normal subjects and to correlate the breath-holding times with pulmonary function tests.

\section{Methods}

We conducted a case-control study in a general, tertiary care, university-affiliated hospital. We included patients with obstructive ventilator defects and a control group consisted of volunteers recruited in the same hospital, with normal spirometry. We excluded patients and controls with severe coronary heart disease, cardiac arrhythmias, pregnancy, acute myocardial infarction, head trauma, glaucoma, hemoptysis, unstable angina, retinal detachment, hypertensive crisis, and pulmonary edema. The local ethics committee approved the study, and all subjects gave written informed consent to participate.

The patients were interviewed and the following data were collected in a standardized questionnaire: demographic data, smoking habits, and presence of comorbidities. Spirometry was performed using a computerized spirometer (Jäeger, Würzburg, Germany), according to the American Thoracic Society/European Respiratory Society guidelines [6-8], and with previously published reference values [9-11].

Breath-holding test was conducted using a pneumotachograph (Hans Rudolph Inc). All measured outputs were displayed in real time on a portable computer. The maximal voluntary apnea inspiratory and expiratory times (MVAIT and MVAET) were measured. For MVAIT collection, subjects were asked to inspire deeply three times, and to stop breathing at last end-inspiration. For MVAET collection, subjects were asked to inspire and expire deeply three times, and to stop breathing at last end-expiration. Each maneuver was repeated three times.

Data analysis was performed using SPSS 16.0 (Statistical Package for the Social Sciences, Chicago, Illinois). Data were presented as number of cases, mean \pm standard deviation (SD), or median

*Corresponding author: Sérgio Saldanha Menna Barreto, Hospital de Clínicas de Porto Alegre, Universidade Federal do Rio Grande do Sul (UFRGS), Brazil, Tel: 55-51-3359-8241; Fax: 55-51-3359-8001; E-mail: smenna@terra.com.br

Received June 20, 2012; Accepted August 02, 2012; Published August 04, 2012

Citation: Viecili RB, Silva DR, Sanches PRS, Müller AF, da Silva DP, et al.(2012) Real-Time Measurement of Maximal Voluntary Breath-Holding Time in Patients with Obstructive Ventilatory Defects and Normal Controls. J Pulmon Resp Med 2:127. doi:10.4172/2161-105X.1000127

Copyright: ( 2012 Viecili RB, et al. This is an open-access article distributed under the terms of the Creative Commons Attribution License, which permits unrestricted use, distribution, and reproduction in any medium, provided the original author and source are credited. 
Citation: Viecili RB, Silva DR, Sanches PRS, Müller AF, da Silva DP, et al.(2012) Real-Time Measurement of Maximal Voluntary Breath-Holding Time in Patients with Obstructive Ventilatory Defects and Normal Controls. J Pulmon Resp Med 2:127. doi:10.4172/2161-105X.1000127

\begin{tabular}{|l|l|l|l|}
\hline Characteristics & Cases $(\mathbf{n}=\mathbf{3 5})$ & Controls $(\mathbf{n}=\mathbf{1 6})$ & $\mathbf{p}$ Value \\
\hline Age (years) & $57.4 \pm 13.1$ & $44.6 \pm 16.8$ & 0.005 \\
\hline Male $(\%)$ & $11(31.4)$ & $5(31.3)$ & 0.990 \\
\hline Smokers & $22(62.9)$ & $5(31.3)$ & 0.036 \\
\hline FVC (L) & $2.80 \pm 0.93$ & $3.51 \pm 0.81$ & 0.012 \\
\hline FEV $($ L) & $1.74 \pm 0.83$ & $3.01 \pm 0.71$ & $<0.0001$ \\
\hline & COPD cases & Controls & p Value \\
\hline MVAIT (s) & $21.6 \pm 12.6$ & $31.5 \pm 15.7$ & 0.049 \\
\hline MVAET (s) & $16.5 \pm 6.0$ & $22.1 \pm 7.9$ & 0.030 \\
\hline & Asthma cases & Controls & p Value \\
\hline MVAIT (s) & $22.9 \pm 11.3$ & $31.5 \pm 15.7$ & 0.076 \\
\hline MVAET (s) & $17.2 \pm 7.2$ & $22.1 \pm 7.9$ & 0.069 \\
\hline
\end{tabular}

Data are presented as mean $\pm \mathrm{SD}$ or $\mathrm{n}(\%)$. $\mathrm{FEV}_{1}$ : forced expiratory volume in one second. FVC: forced vital capacity. MVAIT: maximal voluntary apnea inspiratory time. MVAET: maximal voluntary expiratory time.

Table 1: Characteristics of study patients.

\begin{tabular}{|c|c|c|c|c|c|c|}
\hline \multirow[b]{2}{*}{ Parameter } & \multicolumn{2}{|c|}{ COPD cases $(n=17)$} & \multicolumn{2}{|c|}{ Asthma cases $(n=18)$} & \multicolumn{2}{|c|}{ Controls $(n=16)$} \\
\hline & $r$ & p Value & $\mathbf{r}$ & p Value & $\mathbf{r}$ & p Value \\
\hline FVC (L) & 0.656 & 0.004 & 0.382 & 0.117 & 0.480 & 0.060 \\
\hline FEV $_{1}$ (L) & 0.518 & 0.033 & 0.393 & 0.107 & 0.441 & 0.087 \\
\hline
\end{tabular}

$\mathrm{FEV}_{1}$ : forced expiratory volume in one second. FVC: forced vital capacity. MVAIT: maximal voluntary apnea inspiratory time.

Table 2: Bivariate correlations with MVAIT in cases and controls.

with interquartile range. Pearson's (or Spearman's when indicated) correlations was performed to evaluate for potential relationships between MVAIT/MVAET and FEV $/$ FVC. To find a correlation (at least $r=0.60$ ) between these variables, with a power of $80 \%$ and significance at $5 \%, 19$ patients would be needed. A two-sided $\mathrm{p}$ value $<0.05$ was considered significant for all analyses.

\section{Results}

A total of 35 patients with obstructive ventilatory defects and 16 controls met the inclusion criteria and were included in the analysis, after have gave signed, informed consent. The characteristics of the study population are shown in Table 1.

Patients with obstructive ventilator defects had a mean age of $57.4 \pm$ 13.1 years, significant higher than controls $(44.6 \pm 16.8$ years; $\mathrm{p}=0.005)$. Among cases, 18 had asthma and 17 had COPD. Smoking was more prevalent in cases (62.9\%) than in controls $(31.3 \%)(\mathrm{p}=0.0036)$. Regarding pulmonary function tests, cases had lower values of FVC (L) and $\mathrm{FEV}_{1}(\mathrm{~L})$ than controls $(2.80 \pm 0.93$ vs $3.51 \pm 0.81 ; \mathrm{p}=0.012$ and 1.74 \pm 0.83 vs $3.01 \pm 0.71 ; \mathrm{p}<0.0001$, respectively).

The MVAIT was lower in COPD patients $(21.6 \pm 12.6$ seconds $)$ than in controls (31.5 \pm 15.7 seconds), and this difference was statistically significant $(\mathrm{p}=0.049)$. In addition, MVAET was also lower in COPD cases than in controls $(16.5 \pm 6.0$ vs $22.1 \pm 7.9 ; \mathrm{p}=0.030)$. We did not found statistically significant differences between asthma cases and controls (Table 1).

Using bivariate correlations, we found positive and significant correlations between MVAIT and FVC (L) ( $\mathrm{r}=0.656 ; \mathrm{p}=0.004)$ and between MVAIT and $\mathrm{FEV}_{1}(\mathrm{~L})(\mathrm{r}=0.518 ; \mathrm{p}=0.033)$ in COPD cases (Table 2). MVAET was also correlated with FVC $(\mathrm{L})(\mathrm{r}=0.505 ; \mathrm{p}=0.039)$ and $\mathrm{FEV}_{1}(\mathrm{~L})(\mathrm{r}=0.757 ; \mathrm{p}<0.0001)$ (Table 3$)$. MVAIT and MVAET were correlated neither with FVC (L) nor with $\mathrm{FEV}_{1}(\mathrm{~L})$ in asthma patients and controls (Tables 2 and 3 ).

\section{Discussion}

In this case-control study, we aimed to evaluate if MVAIT and
MVAET were different in patients with obstructive ventilatory defects and control subjects, and if there was an association between pulmonary function tests and MVAIT/MVAET. We demonstrated that MVAIT and MVAET were significant lower in COPD cases than in controls, and that these measures were correlated positively with $\mathrm{FVC}$ and $\mathrm{FEV}_{1}$ in COPD patients.

Breath-holding is one of the most powerful methods to induce the dyspneic sensation, and gives much information on the onset and endurance of dyspnea. In conscious subjects, immediately after the start of breath-holding at functional residual capacity (FRC), there is a certain period of no particular respiratory sensation lasting for 20-30 s. This period is terminated by the onset of dyspnea and followed by a progressive increase in the intensity of dyspnea until the breaking point of breath-holding. The measurement of the period of no respiratory sensation provides us with information about the threshold of dyspneic sensation whereas the measurement of the total breath-holding time is a behavioral measure of the tolerable limit of dyspneic sensation [12].

We found that the maximal voluntary apnea inspiratory and expiratory times were significant lower in patients with obstructive ventilatory defects with COPD diagnosis than in control subjects. Moreover, using bivariate correlations, we demonstrated positive correlations between MVAIT/MVAET and pulmonary function parameters $\left(\mathrm{FVC}\right.$ and $\left.\mathrm{FEV}_{1}\right)$. Although an earlier study suggested that breath-holding test was not useful as a pulmonary function test [13], several studies proved that this test may play a role in evaluation of dyspnea [3-5,14].

The ability of hold the breath varies with the individual and with different conditions. In a study that evaluated a sequential measurement of MVAIT in postoperative period, the authors found that this test was easy of execution, had a good acceptation, and was an interesting tool to clinical follow-up after surgery, helping to detect complications in this period [5]. Breath-holding test was also used combined with Borg scale and $\mathrm{FEV}_{1} / \mathrm{FVC} \%$ to detect low perception of dyspnea in asthmatics patients [4]. In addition, a recent study [3] demonstrated another possible contribution of breath-holding-test. In smokers and/ or overweight subjects, breath-holding test induces higher than normal transient desaturation, even when their spirometry data were normal.

Our study has some limitations. First, the investigation was done in a single center. Second, it must be considered that this study was conducted with a small sample size. Despite these limitations, our results provide additional evidence of usefulness of MVAIT/MVAET as pulmonary function tests.

In conclusion, in this study we found that MVAIT and MVAET were significant lower in patients with obstructive ventilatory defects with COPD diagnosis than in controls, and that MVAIT/MVAET were correlated positively with FVC and $\mathrm{FEV}_{1}$ in this subgroup of patients. The breath-holding test may be useful to help recognize potentially severe future lung abnormalities and to promote more effective behavioral intervention. Nevertheless, new studies are necessary to prove the usefulness of breath-holding test especially as a tool for screening in the evaluation of dyspnea.

\begin{tabular}{|l|l|l|l|l|l|l|}
\hline \multirow{2}{*}{ Parameter } & \multicolumn{2}{|l|}{ COPD cases (n=17) } & \multicolumn{2}{l|}{ Asthma cases (n=18) } & \multicolumn{2}{l|}{ Controls (n=16) } \\
\cline { 2 - 8 } & $\mathbf{r}$ & $\mathbf{p}$ Value & $\mathbf{r}$ & $\mathbf{p}$ Value & $\mathbf{r}$ & $\mathbf{p}$ Value \\
\hline FVC (L) & 0.505 & 0.039 & 0.094 & 0.711 & 0.453 & 0.078 \\
\hline FEV $\mathbf{1}$ (L) & 0.757 & $<0.0001$ & 0.106 & 0.675 & 0.351 & 0.182 \\
\hline
\end{tabular}

$F_{1}$ : forced expiratory volume in one second. FVC: forced vital capacity. MVAET: maximal voluntary apnea expiratory time.

Table 3: Bivariate correlations with MVAET in cases and controls. 
Citation: Viecili RB, Silva DR, Sanches PRS, Müller AF, da Silva DP, et al.(2012) Real-Time Measurement of Maximal Voluntary Breath-Holding Time in Patients with Obstructive Ventilatory Defects and Normal Controls. J Pulmon Resp Med 2:127. doi:10.4172/2161-105X.1000127

\section{Authors' Contributions}

RBV participated in the conception of the study, in its design, collected the data, and helped to draft the manuscript. DRS performed the statistical analysis and wrote the manuscript. PRSS, AFM and DPS participated in the conception of the study, and in its design. SSMB participated in the conception of the study, in its design, and helped to draft the manuscript.

\section{Acknowledgements}

Funding source: FIPE - Hospital de Clínicas de Porto Alegre

\section{Reference}

1. Mitrouska I, Tsoumakidou M, Prinianakis G, Milic-Emili J, Siafakas NM (2007) Effect of voluntary respiratory efforts on breath-holding time. Respir Physiol Neurobiol 157: 290-294.

2. Parkes MJ (2006) Breath-holding and its breakpoint. Exp Physiol 91: 1-15.

3. Inoue H, Yamauchi K, Kobayashi H, Shikanai T, Nakamura Y, et al. (2009) A new breath-holding test may noninvasively reveal early lung abnormalities caused by smoking and/or obesity. Chest 136: 545-553.

4. Nannini LJ, Zaietta GA, Guerrera AJ, Varela JA, Fernandez OM, et al. (2007) Breath-holding test in subjects with near-fatal asthma. A new index for dyspnea perception. Respir Med 101: 246-253.

5. Pinheiro CTS, Barreto SSM, Gottschall CAM (1994) Sequential measurement of the maximum time of inspiratory apnea in the postoperative period. $J$ Pneumol 20: 16-23.

6. Maclntyre N, Crapo RO, Viegi G, Johnson DC, van der Grinten CP, et al. (2005) Standardisation of the single-breath determination of carbon monoxide uptake in the lung. Eur Respir J 26: 720-735.

7. Miller MR, Hankinson J, Brusasco V, Burgos F, Casaburi R, et al. (2005) Standardisation of spirometry. Eur Respir J 26: 319-338.

8. Wanger J, Clausen JL, Coates A, Pedersen OF, Brusasco V, et al. (2005) Standardisation of the measurement of lung volumes. Eur Respir J 26: 511 522.

9. Crapo RO, Morris AH, Gardner RM (1981) Reference spirometric values using techniques and equipment that meet ATS recommendations. Am Rev Respir Dis 123: 659-664.

10. Crapo RO, Morris AH (1981) Standardized single breath normal values for carbon monoxide diffusing capacity. Am Rev Respir Dis 123: 185-189.

11. Crapo RO, Morris AH, Clayton PD, Nixon CR (1982) Lung volumes in healthy nonsmoking adults. Bull Eur Physiopathol Respir 18: 419-425.

12. Nishino T (2009) Pathophysiology of dyspnea evaluated by breath-holding test: studies of furosemide treatment. Respir Physiol Neurobiol 167: 20-25.

13. Gaensler EA, Rayl DF, Donnelly DM (1951) The breath holding test in pulmonary insufficiency; evaluation of 1,000 studies. Surg Gynecol Obstet 92: 81-90.

14. Barreto SSM, Gottschall CAM (1978) Comparação entre provas espirométricas e testes clínico-funcionais pulmonares. J Pneumol 4: 21-29. 